\title{
THE EFFECT OF EXTREMES OF TEMPERATURE ON HERRING LARVAE
}

\author{
By J. H. S. BLAXTeR \\ Marine Laboratory, Aberdeen
}

(Text-fig. I)

Most of the work on temperatures lethal to fish has been reviewed by Brett (1956). Most of the fish have been adults of freshwater species, and it has been found that both upper and lower lethal temperatures vary with the species, the temperature of acclimatization and the duration of time the fish are subjected to the test temperature.

Experiments on the upper and lower lethal temperatures for herring larvae (Clupea harengus L.) were started for three reasons: (I) to find out the range of temperature the larvae could withstand in rearing experiments at different acclimatization temperatures, this being part of a programme to determine the tolerance of herring larvae to a number of environmental factors (Holliday \& Blaxter, I960); (2) to look for possible differences in temperature tolerance between larvae from spring- and autumn-spawned herring (see Blaxter, I958, for a discussion of this problem); and (3) to obtain some idea of what danger larvae might experience if subjected to rises of temperature in the sea caused by effluents or hot weather.

\section{MATERIALS AND METHODS}

Ripe gonads were dissected from spring-spawning herring caught in the Firth of Clyde in February I957 and from autumn-spawning herring caught off the East Coast of Scotland in September 1957. The gonads were stored at $4^{\circ} \mathrm{C}$ (Blaxter, 1955) and transported to the laboratory, where the eggs were fertilized and hatched in tanks holding 501 . of sea water (Blaxter, 1956). In February three tanks were used and maintained at different incubation temperatures $\left(7.5,11 \cdot 0,15.0^{\circ} \mathrm{C}\right)$. In September tanks at temperatures of II and $15.5^{\circ} \mathrm{C}$ only were used. These were also the acclimatization temperatures for the succeeding experiments.

Hatching occurred 7-I 5 days after fertilization, depending on the incubation temperature. The larvae were then $6-8 \mathrm{~mm}$ long and possessed yolk sacs. Within 2 days of hatching batches of ten larvae were transferred by a pipette from the incubation tanks to jars holding $500 \mathrm{ml}$. of sea water at the temperature of incubation. These jars were then placed in baths holding water 
at the test temperatures. The high-temperature baths, for testing the upper lethal temperatures, were maintained at their temperature by low-power immersion heaters controlled by thermostats. The low-temperature baths were either kept in a refrigerator or were cooled by glycerol from a refrigeration unit. The glycerol was circulated through a cooling coil by a small centrifugal pump controlled by a thermostat.

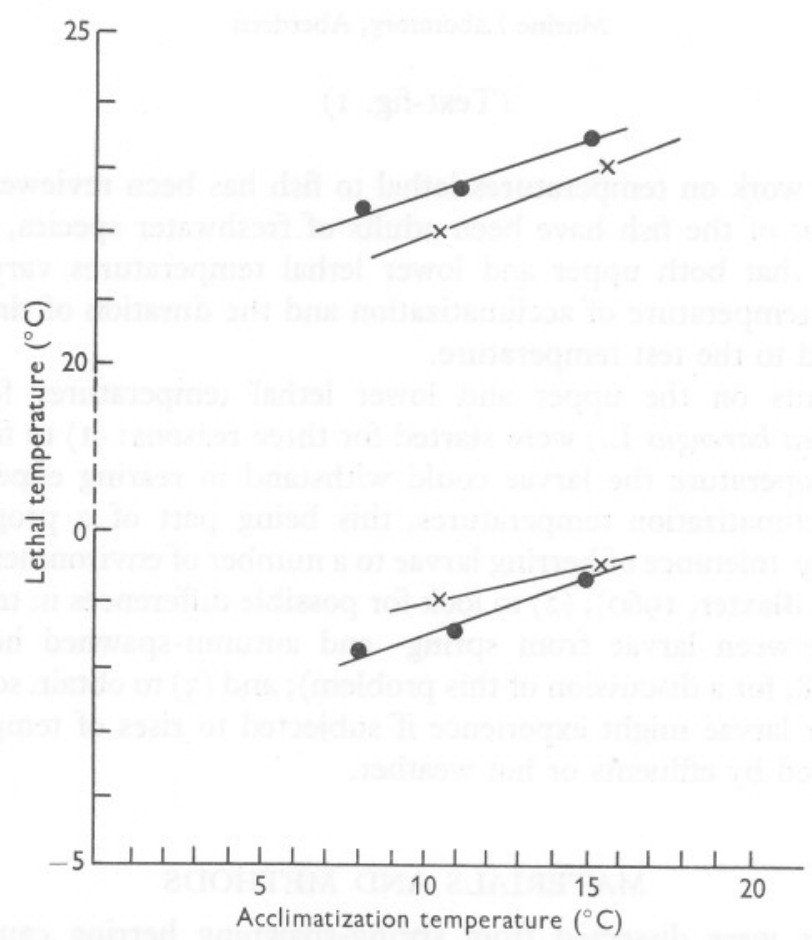

Fig. I. Lethal temperatures for spring-spawned herring larvae $(-\bullet)$ and autumn-spawned larvae $(x-x)$ at different acclimatization temperatures.

The temperature of the water in the $500 \mathrm{ml}$. jars reached the test temperature within $\mathrm{I} \mathrm{h}$. Although continuous records were not kept, no observation of the test temperature showed a fluctuation greater than $\pm 0 \cdot \mathrm{I}^{\circ} \mathrm{C}$ during an experiment.

The numbers of larvae which were moribund or dead after $24 \mathrm{~h}$ at the test temperatures were counted. Larvae were called moribund when they had started to turn opaque though the heart continued to beat. Tests showed that this condition was not reversible. The scale of test temperatures (each one differing by about $0.5^{\circ} \mathrm{C}$ from the next) was such that at one end all the larvae survived and at the other at least $50 \%$ were moribund or dead. 


\section{RESULTS}

The lethal temperatures, in this case defined as the temperature at which $50 \%$ of the larvae died or became moribund after a $24 \mathrm{~h}$ period of exposure, were determined in the following way. For each acclimatization temperature a graph was drawn of the percentage of larvae dead or moribund after $24 \mathrm{~h}$ at each test temperature. By interpolation the temperature at which $50 \%$ died or became moribund was determined. The lethal temperatures for both spring- and autumn-spawned larvae are plotted against the acclimatization temperature in Fig. I. It will be seen that the range of lethal temperature is less for autumn- than for spring-spawned larvae. This difference was checked by probit analysis and found to be not significant.

\section{DISCUSSION}

The upper lethal temperatures $\left(22-24^{\circ} \mathrm{C}\right)$ for herring larvae acclimatized to $7.5^{-1} 5^{\circ} 5^{\circ} \mathrm{C}$ are very similar to those $\left(22-25^{\circ} \mathrm{C}\right.$, over the same acclimatization range) for five species of salmonid fry studied by Brett (1952). The lower lethal temperatures for the herring larvae are, however, $-0.75^{\circ} \mathrm{C}$ to $-\mathrm{I} \cdot 8^{\circ} \mathrm{C}$, compared with $\mathrm{I}-5^{\circ} \mathrm{C}$ for the salmonid species. Colton (1959) observed mortality at sea among the larvae of Limanda ferruginea and Merluccius bilinearis when they had probably been subjected to a rise in temperature from 6.7 to $17.8^{\circ} \mathrm{C}$ in $24 \mathrm{~h}$. Kuthalingam (1959) found that the tolerance range for the larvae of ten species of tropical fish was very narrow, the upper lethal temperature varying from 30 to $3 \mathrm{I}^{\circ} \mathrm{C}$ and the lower one from 27 to $29^{\circ} \mathrm{C}$.

Although the test period of $24 \mathrm{~h}$ used in these experiments is an arbitrary one, it has been quite generally used in the past. Since the work of Doudoroff (1945) and Fry, Hart \& Walker (1946) it has been more usual to determine the lethal temperatures by plotting the percentage dying at a given temperature against time. These authors found in nearly every test that all deaths occurred within the first $24 \mathrm{~h}$ at upper lethal temperatures. For lower lethal temperatures, deaths may continue to occur for up to 5 or 6 days depending on the test temperature. It has not been practicable to use this technique for herring larvae on hatching as they only survive this stage for about I week to Io days and a sufficient number of experiments could not be carried out in this time. The upper lethal temperatures obtained in these experiments, then, may be compared with those determined by different criteria, but the lower lethal temperatures are probably rather lower than might be obtained by longerterm experiments.

Although the lethal temperature differences between spring- and autumnspawned larvae are not significant, other physiological differences have been shown between larvae from spring- and autumn-spawning herring (Blaxter, 
I956), and both Hart (I952) and McCauley (1958) have shown that lethal temperatures may vary in different races of the same species.

Thanks are due to my colleague $\mathrm{Mr} \mathrm{W}$. Hall for his help with the statistical treatment of the results.

\section{SUMMARY}

For herring larvae 6-8 mm long, acclimatized to temperatures between $7 \cdot 5$ and $15.5^{\circ} \mathrm{C}$, the upper lethal temperature (defined as that temperature at which $50 \%$ of the fish die or become moribund after $24 \mathrm{~h}$ ) varies from 22 to $24^{\circ} \mathrm{C}$ and the lower lethal temperature from -0.75 to $-\mathrm{I} \cdot 8^{\circ} \mathrm{C}$.

The range of temperature tolerance is slightly less for autumn-spawned larvae than for spring-spawned larvae though this difference is not significant.

\section{REFERENCES}

Blaxter, J. H. S., I955. Herring rearing. I. The storage of herring gametes. Mar. Res. Scot., 1955, No. 3, I2 pp.

1956. Herring rearing. II. The effect of temperature and other factors on development. Mar. Res. Scot., 1956, No. 5, I9 pp.

- 1958. The racial problem in herring from the viewpoint of recent physiological, evolutionary and genetical theory. Rapp. Cons. Explor. Mer, Vol. I43, No. 2, pp. IO-I9.

BretT, J. R., 1952. Temperature tolerance in young Pacific salmon, genus Oncorhynchus. F. Fish. Res. Bd Can., Vol. 9, pp. 265-323.

- 1956. Some principles in the thermal requirements of fishes. Quart. Rev. Biol., Vol. 31, pp. 75-87.

Colton, J. B., Jr., 1959. A field observation of mortality of marine fish larvae due to warming. Limnol. Oceanogr., Vol. 4, pp. 219-22.

DoudorofF, P., I945. The resistance and acclimatization of marine fishes to temperature changes. II. Experiments with Fundulus and Atherinops. Biol. Bull., Woods Hole, Vol. 88, pp. 194-206.

FrY, F. E. J., HART, J. S. \& WALKER, K. F. 1946. Lethal temperature relations for a sample of young speckled trout (Salvelinus fontinalis). Publ. Ont. Fish. Res. Lab., No. 66, 35 pp.

HART, J. S., I952. Geographic variations of some physiological and morphological characters in certain freshwater fish. Publ. Ont. Fish. Res. Lab., No. 72, 79 pp.

Holliday, F. G. T. \& BlaxteR, J. H. S., I960. The effects of salinity on the developing eggs and larvae of the herring. F. mar. biol. Ass. U.K., Vol. 39, pp. 591-603.

Kuthalingam, M. D. K., I959. Temperature tolerance of the larvae of ten species of marine fishes. Curr. Sci., Vol. 28, pp. 75-6.

McCauley, R. W., 1958. Thermal relations of geographic races of Salvelinus. Canad. f. Zool., Vol. 36, pp. 655-62. 